\title{
Glycoregulatory Enzymes as Early Diagnostic Markers during Premalignant Stage in Hepatocellular Carcinoma
}

\author{
NM Abdel-Hamid ${ }^{1, *}$, MF Ramadan², SW Amgad ${ }^{2}$ \\ ${ }^{1}$ Departments of Biochemistry, Colleges of Pharmacy, Kafrelsheikh University, Kafrelsheikh \\ ${ }^{2}$ Departments of Biochemistry, Colleges of Pharmacy, Minia University, Minia, Egypt \\ *Corresponding author: nabilmohie@yahoo.com
}

Received January 07, 2013; Revised April 24, 2013; Accepted April 25, 2013

\begin{abstract}
Hepatocellular carcinoma (HCC) is the third leading cause of death and fifth most common malignancy worldwide. Objective: Present study focused on the abnormal tumor cell glucose metabolism, considering the pathways of hexose monophosphate (HMP) shunt enzymes. The key regulatory enzymes of HMP include hexokinase (HK), glyeraldehyde-3-phosphate dehydrogenase (GAPDH) and glucose-6-phosphate dehydrogenase (G6PD). Their perturbations sought to be helpful in the diagnosis and prognosis of HCC in addition to alphafetoprotein (AFP). Materials and methods: Diethyl nitrosamine (DENA) plus carbon tetra chloride (CCl4) chemically-induced HCC model was used. Sixteen male albino rats were equally divided into 2 groups. Group I: served as a normal control received single intraperitonial (I.P) injection of saline, 2 weeks later, received subcutaneous (S.C) injection of saline, in equal volumes given for group II animals. Group II animals received single I.P injection of DENA (200mg/kg), 2 weeks later, received S.C injection of CCl4 (3ml/Kg/week) for 6 weeks. Then animals were sacrificed, blood and liver samples were obtained. Results: In HCC group, relative liver weights, serum AFP and HK, GAPDH and G6PD activities in both serum and liver homogenate were significantly increased; subsequent decrease in body weight was also evident. The histopathological examination of liver biopsies revealed the presence of few dysplastic nodules. Such nodules were $1 \mathrm{~mm}$ or more in diameter on macroscopic examination, indicating carcinogenic features, nuclear and cytoplasmic alterations with clustering of population cells, structurally abnormal portal tracts, supporting serum enzyme and tumor marker assays. Conclusion: Glycolytic alterations can be used for diagnosis and prognosis of carcinogenesis in liver. These biomarkers may be beneficial tools to improve diagnostic performance of conventional tumor markers as AFP.
\end{abstract}

Keywords: alpha fetoprotein, diagnosis, hepatocellular carcinoma, glycoregulatory enzymes

\section{Introduction}

Hepatocellular carcinoma (HCC) is the fifth most common cancer worldwide, and its incidence will further increase, to reach a plateau in 2015-2020 [1]. It is a major health problem worldwide, involving more than half a million new cases yearly. HCC develops most often in cirrhotic liver and this condition is the strongest predisposing factor $[2,3]$. Chronic carriers of hepatitis B virus (HBV) have a 100 -fold relative risk for developing HCC, with an annual incidence rate of $2 \%-6 \%$ in cirrhotic patients. Other causes of HCC include alcoholic liver cirrhosis and aflatoxin B [4,5]. The rates of HCC in men are 2 to 4 times higher than in women [6,7]. Without specific treatment, the prognosis is very poor [7]. Numerous experimental models have been developed to define the pathogenesis of $\mathrm{HCC}$ and to test novel diagnostic parameter candidates. This study analyzes Diethylnitrosamine (DENA) model with CCL4 for HCC research. Frequently, cancer cells possess an abnormal pattern of energy metabolism when compared to normal cells [8]. During the progression of tumours, the genetic and epigenetic alterations accumulate and the rapidly growing tumours need to overcome hypoxia and nutrient deprivation owing to the inadequate blood supply, leading to changes in the energy demands of cancer cells $[9,10]$. Glucose is the primary energy source and high rate of glycolysis is one of the earliest discovered hallmarks of cancer, it provides the tumour with metabolic and survival advantages [11,12].

DENA is a potent carcinogenic dialkylnitrosoamine used to induce liver cancer in animal models. DENA belongs to the group of $\mathrm{N}$-nitrosamines, causing a wide range of tumours in all animal species and suspected to be health hazards to man $[13,14]$.

HCC has become a prevalent disease in many populations worldwide. It initiates many economic problems in management modalities and leads to increasing mortality rates. Many trials are carried out all over the world to implement specific early markers for detection and prediction of this disease, hoping to set a more precise strategy for liver cancer prevention $[4,15]$.

Elevated glucose catabolism is important for the production of energy and required anabolic precursors in rapidly growing tumour. It was established that abnormalities of glucose metabolizing enzymes in the transformation of normal livers is referred to high glucose utilization in hepatoma cells [16]. 
Surprisingly, tumour cells often metabolize glucose to lactate even in the "presence" of oxygen which is called aerobic glycolysis. This is unusual and stands in contrast to normal cells that only metabolize glucose to lactate in the "absence" of oxygen. The high rate of aerobic glycolysis exhibited by some cancer cells is called the Warburg effect, in recognition of Otto Warburg's discovery. Based on this observation Warburg championed the idea that aerobic glycolysis is a pathway during carcinogenesis $[17,18,19]$.

Since a definite correlation exists between tumour progression and the activities of glycolytic enzymes [20,21] such as Hexokinase (HK), Glyeraldehyde-3phosphate dehydrogenase (GAPDH) and Glucose-6phosphate dehydrogenase (G6PD), the assessment of alterations in their activity can be used as helpful markers for diagnosis of HCC. Serological markers for HCC are important for early diagnosis, as well as monitoring of tumour aggressiveness [22].

\section{Materials and Methods}

\subsection{Animals}

Sixteen adult male Albino rats of Wister strain weighing 150-200g, supplied by animal house of Biochemistry Department, Faculty of Agriculture, Minia University, were used for experimental investigation in this study. Animals were kept for 2 weeks to accommodate with the laboratory conditions, they were kept under constant environmental and nutritional conditions then were given food and water all over the period of the experiment.

\subsection{Chemicals}

DENA and $\mathrm{CCl}_{4}$ were purchased from Sigma Chemical Co. (St. Louis, MO, USA). All other chemicals used were of analytical grade.

\subsection{Experimental Design}

The rats were classified into 2 groups each of 8 rats. Group I: Untreated normal healthy group, were given saline only (intraperitoneal(I.P), 2 weeks later, received subcutaneous ( S.C) injection of saline (3ml/Kg/ week) for 6 weeks. Group II (DENA+CCl4): received single I.P injection of DENA (200mg/Kg body weight), freshly dissolved in sterile $0.9 \%$ saline. Two weeks later, received S.C injection of $\mathrm{CCl}_{4}(3 \mathrm{ml} / \mathrm{Kg} /$ week) for 6 weeks as it promotes the carcinogenic effect of DENA [23,24,25] (HCC-induction group).

\subsection{Preparation of Serum and Liver Homogenate}

At the end of the experimental period (8 weeks), rats were food-deprived overnight and were sacrificed. This period was the maximum tolerable period to animals against mortalities. Blood was collected and allowed to clot before centrifugation at 4000rpm for $10 \mathrm{~min}$ to separate serum and samples were stored as aliquots in Eppendorff Tubes (2 cc size) and frozen at $-80^{\circ} \mathrm{C}$. The livers were immediately excised, rinsed with ice-cold saline and blotted to dry and accurately weighed. The relative liver weight for each rat was calculated as the percentage ratio of liver weight to the body weight. Half of liver size was used for the histopathological studies while the remaining half was used for the preparation of homogenate.

Ten percent homogenate was prepared in $0.1 \mathrm{M}$ Tris$\mathrm{HCl}$ buffer ( $\mathrm{pH}$ 7.4) using a Potter-Elvehjem homogenizer with a Teflon pestle. Then, liver homogenates were centrifuged at 4000rpm for 15 minutes and the supernatant was collected for determination of enzyme activity and stored as aliquots in Eppendorff Tubes and kept at $-80^{\circ} \mathrm{C}$.

\subsection{Histopathological Assessment}

Liver sections were made immediately from the livers of animals of the two groups, fixed in $10 \%$ formalin for histopathological studies. Serial paraffin sections ( $4 \mu$ thick) were cut from each specimen then stained with Haematoxylin and Eosin (H\&E).

\subsection{Biochemical Analysis}

Serum alpha fetoprotein (AFP) level was measured by solid phase enzyme linked immuno sorbent assay (ELISA), using Calbiotech AFP Kit (USA) following the instructions of the manufacturer.

Enzyme activities of, HK [26], GAPDH [27] and G6PD [28], were assayed spectrophotometrically in the serum and liver tissue homogenate. Total protein concentration in the supernatants of tissue homogenates was spectrophotometrically determined according to Gornall and Bardawill (1949) (data are not shown) [29] .

\subsection{Definitions of Unit and Specific Activity}

One unit of $\mathrm{HK}$ activity reduces one micromole of $\mathrm{NADP}^{+}$per minute at $\mathrm{pH} 7.6$ at $25^{\circ} \mathrm{C}$. One unit of GAPDH activity reduces one micromole of $\mathrm{NAD}^{+}$per minute at $25^{\circ} \mathrm{C}$ and $\mathrm{pH}$ 8.5. One unit of G6PD activity reduces one micromole of $\mathrm{NADP}^{+}$per minute at $\mathrm{pH} 7.6$ at $25^{\circ} \mathrm{C}$. Specific activity of HK, GAPDH and G6PD were expressed as units per milligram of protein [30].

\subsection{Statistical Analysis}

The results were presented as group means \pm SD and statistically significant differences between mean values were determined by one way analysis of variance (ANOVA). Values of $<0.05$ were considered statistically significant. Graph Pad Prism v.5.0 software was used for this analysis.

\section{Results}

\subsection{Body Weight and Relative Liver Weight}

There was a slight decrease in the final body weight of rats subjected to DENA and $\mathrm{CCl}_{4}$ as compared to the normal control group. In premalignant HCC group (group II) the increase in relative liver weight (liver weight/ body weight ratio) was significant, compared to normal control (Gp I).

\subsection{Biochemical Assays}

DENA+CCl4 caused a significant increase in the serum level of AFP (group II), compared to normal control 
(Table 2). The activities of HK, GAPDH and G6PD in serum and liver tissue homogenates are shown in Table 2, Table 3 respectively. DENA+CCl4 significantly increased the activities of HK, GAPDH and G6PD in serum and liver tissue homogenate of premalignant HCC group (II), compared to normal control.

Table 1. Effect of HCC chemical induction on body weight and relative liver weights

\begin{tabular}{|c|c|c|c|}
\hline Groups & $\begin{array}{c}\text { Final body } \\
\text { weight (g) }\end{array}$ & $\begin{array}{c}\text { Liver weight } \\
(\mathrm{g})\end{array}$ & $\begin{array}{c}\text { Relative liver } \\
\text { weight }\end{array}$ \\
\hline I (Control) & $228.5 \pm 8.8$ & $5.8 \pm 0.4$ & $2.508 \pm 0.1$ \\
\hline $\begin{array}{c}\text { II } \\
\text { (premalignant } \\
\text { HCC) }\end{array}$ & $203.1 \pm 5.7^{*}$ & $6.934 \pm 0.5$ & $3.401 \pm 0.1^{* * *}$ \\
\hline
\end{tabular}

Relative liver weight: percentage ratio of liver weight to the body weight. Data are expressed as $\mathrm{M} \pm \mathrm{SD}(\mathrm{n}=8) .\left({ }^{*} \mathrm{P}<0.05\right.$, $\left.{ }^{* * *} \mathrm{P}<0.001\right)$.

Table 2. Serum levels of AFP and enzyme activities of HK, GAPDH and G6PD in premalignant HCC group compared to non treated control

\begin{tabular}{|c|c|c|}
\hline $\begin{array}{c}\text { Groups } \\
\text { Parameter }\end{array}$ & $\begin{array}{c}\text { Normal } \\
\text { control (I) }\end{array}$ & Premalignant HCC-group (II) \\
\hline AFP (ng/ml) & $4.04 \pm 0.6$ & $61.1 \pm 2.71 * * *$ \\
\hline HK (mU/ml) & $5.74 \pm 2.0$ & $9.84 \pm 1.7 * *$ \\
\hline GAPDH $(\mathrm{mU} / \mathrm{ml})$ & $25.32 \pm 3.4$ & $33.16 \pm 5.4 * *$ \\
\hline G6PD $(\mathrm{mU} / \mathrm{ml})$ & $0.50 \pm 0.38$ & $2.38 \pm 0.44 * * *$ \\
\hline
\end{tabular}

Data are expressed as $\mathrm{M} \pm \mathrm{SD}(\mathrm{n}=8)$. HCC-induction group is compared with normal control, $(* * \mathrm{P}<0.01, * * * \mathrm{P}<0.001)$.
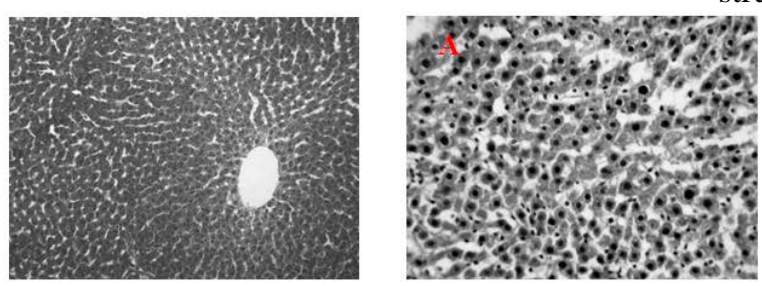

Normal Control

(Hemotoxylin and Eosin, $\mathrm{X}=$ 200).

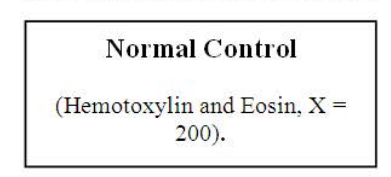

Table 3. Enzyme activities of HK, GAPDH and G6PD in liver tissue homogenates of premalignant HCC group compared to non treated control

\begin{tabular}{|c|c|c|}
\hline $\begin{array}{c}\text { Groups } \\
\text { Parameter }\end{array}$ & Normal Control (I) & HCC-induction (II) \\
\hline HK (mU/mg protein) & $7.926 \pm 2.319$ & $15.58 \pm 2.725 * * *$ \\
\hline $\begin{array}{c}\text { GAPDH (mU/mg } \\
\text { protein) }\end{array}$ & $28.34 \pm 4.025$ & $46.42 \pm 8.907 * * *$ \\
\hline G6PD (mU/mg protein) & $3.425 \pm 1.316$ & $6.750 \pm 0.707 * * *$ \\
\hline
\end{tabular}

Data are expressed as $\mathrm{M} \pm \mathrm{SD}(\mathrm{n}=8)$. HCC-induction group is compared with normal control, $\left({ }^{* * *} \mathrm{P}<0.001\right)$.

\subsection{Histopathological studies}

Histopathological examination of liver sections from control group revealed normal hepatic lobular architecture and hepatocytes with granulated cytoplasm and small uniform nuclei and nucleoli. In contrast, HCC induction with DENA $+\mathrm{CCl}_{4}$ showed premalignant features as hydropic degeneration with cloudy swelling of most liver cells in the form of ballooning of cells with foamy cytoplasm due to intracellular accumulation of water. Examined liver sections showed fatty changes, necrotic features, congestion of portal tract with proliferated bile ductules, infiltration with some polymorph nuclear leucocytes (PMNLs) and inflammatory signs. Examination of livers from premalignant HCC group has revealed the presence of few dysplastic nodules. Such nodules were $1 \mathrm{~mm}$ or more in diameter on macroscopic examination. The histopathological examination of liver tissue sections harboring such nodules has shown the presence of nuclear and/or cytoplasmic alterations with clustering of such population cells. Portal tracts were structurally abnormal (Figure 1):
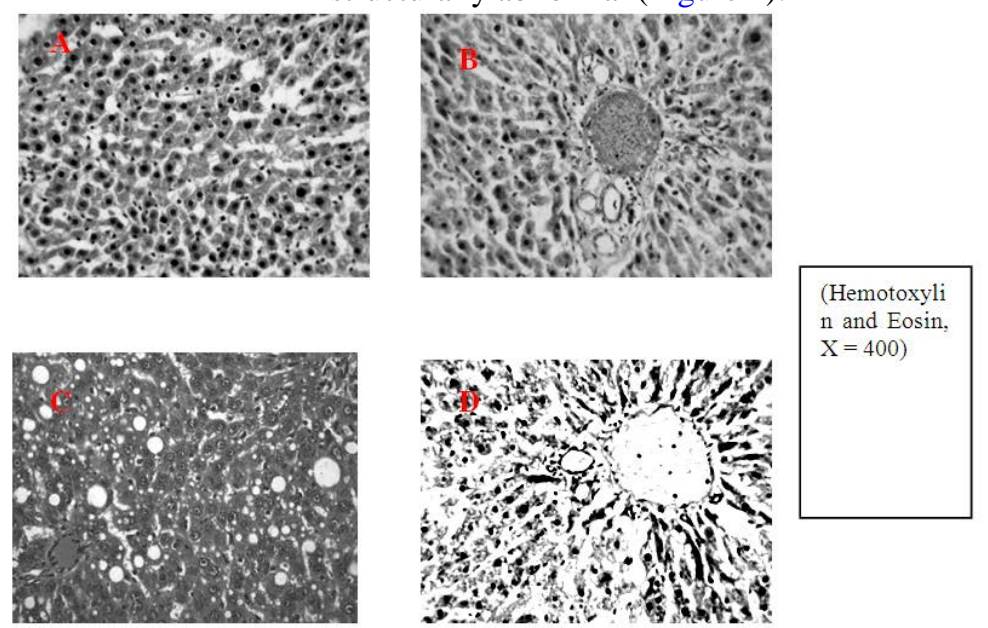

Figure 1. Representative photomicrographs of liver section from premalignant HCC and control groups. (A) Animals treated with DENA and CCl . (B) Cross section showed portal tract with markedly congested branch of portal vein, proliferated bile ductules, bile stasis and infiltration with some inflammatory cells. (C) Examined section demonstrates fatty changes (both micro and macro vesicular) and necrosis. (D) Examined section shows hydropic degeneration, fatty change and severe necrosis

\section{Discussion}

Hepatocellular carcinoma incidence is expected to increase, to reach a plateau in 2015-2020 [31]. It represents a health problem worldwide, involving more than half a million new cases yearly. Cirrhotic liver is the strongest predisposing factor for developing HCC [2,3]. Chronic carriers of HBV have a 100 -fold relative risk for developing HCC. Other morbidifying factors include, diabetes mellitus, Schistosomiasis,. alcoholism, food and water pollutants, some drugs, some hereditary diseases, as hemochromatosis, $\alpha$-1-antitrypsin deficiency and tyrosinaemia were reported to lead to the development of HCC [4]. The rates of HCC in men are 2 to 4 times higher than in women [6,7], without early management, the prognosis is very poor [7].

HCC is one of the most common cancers worldwide that typically occurs on top of cirrhosis and chronic hepatitis virus infections [32]. Metabolic activation of DENA by cytochrome P450 enzymes is responsible for its cytotoxic, mutagenic and carcinogenic effects [33,34].

In the present study, animals treated with DENA plus CCl4 exhibited a significant depression of body growth 
with increased liver weights and microscopically detectable premalignant liver tumors. The histopathological examination of liver biopsies showed some of reversible cell injury as hydropic degeneration, fatty change in addition to inflammatory cellular infiltrate. Such findings strongly suggest the ability of DENA to initiate hepatocarcinogenesis with the synergistic effect of CCl4. Such results are in agreement with those findings reported by other studies [24,25,35,36].

Examination of livers from experimentally-induced HCC (group II) also revealed the presence of few dysplastic nodules. Dysplastic nodules are generally considered an important precursor to HCC [37]. Dysplastic nodules do not regress and often increase in size [38]. DENA and CCl4 generally reflect instability of liver cell metabolism which leads to distinctive changes in the enzyme activities and serum level of AFP [39]. It has long been recognized that exposure of rats to certain carcinogens like DENA increases the circulating AFP levels [40]. As the sensitivity of AFP is not always enough [39], we focused our efforts to find biochemical markers for hepatomalignancy to be used in addition to morphologic and histopathologic criteria. Malignant tumors turn on extensive glycolysis as a source of ATP $[17,18,19,41]$.

HCC receives blood from the hepatic artery and hypoxia forces the cancer cells to make a metabolic switch to ensure the energy sources [42]. The crucial role of glucose utilization to HCC growth was confirmed by HCC cell lines that undergone acute cell death upon glucose starvation [43,44]. Further study demonstrated an increased glycolysis and a decreased glycogenesis in liver cancer [45]. Several key genetic alterations associated with tumor development were recently shown to affect glycolysis directly, such as p53 mutation and the activation of hypoxia inducible factor (HIF) [46,47].

Hexokinase (D-hexose-6-phosphotrnsferase) is a key enzyme of glycolysis. Four isozymes are known; according to their anodal electrophoretic mobility at $\mathrm{pH}$ 8.6, designated as I through IV [48]. Increased activity of $\mathrm{HK}$ in tumor cells is responsible for the increased aerobic glycolysis [45,49]. Higher levels of HKII, have been elevated in tumor tissue compared to normal tissue [50,51]. Considerable investigations have been carried out to characterize HK activity in liver tumors [52,53]. Rat hepatoma AS-30D, demonstrated that HK activity was approximately 100-fold higher than in normal liver tissue, most closely related to isoenzyme HK-II [53].

Targeted gene therapy using a rat tumor-specific HK II promoter has been reported to be successful [54]. The changes in tissue content in our study were accompanied by same changes as an increased enzyme activity in blood, which announces for seromarker utility.

Glyceraldehyde 3-Phosphate Dehydrogenase (GAPDH) contains critical thiols, it initiates the second stage of glycolysis [55]. It is involved in intracellular processes such as membrane fusion, microtubule bundling, phosphotransferase activity, nuclear RNA export, DNA replication and repair. GAPDH plays a role in different pathologies including prostate cancer progression, programmed neuronal cell death and age-related neuronal diseases, i.e. Alzheimer's and Huntington's disease $[56,57,58]$. The etiology(s) of serum GAPDH elevation remains unclear, but one possible source is increased leakage of the GAPDH molecule into the serum from damaged cirrhotic hepatocytes underlying hepatocarcinogenesis or chronic inflammation [59]. The changes in tissue content in our study were accompanied by parallel changes as an increased enzyme activity in blood, which announces for seromarker utility.

Glucose-6-phosphate dehydrogenase is the first enzyme in the pentose phosphate pathway, a major source of NADPH and ribose 5-phosphate which is necessary for nucleotide biosynthesis [60]. Its overexpression increases resistance to H2O2-induced cell death and G6PD inhibition induced a significant increase in apoptosis [61].Thus, a reduction in NADPH supply could have a profound effect on oxygen-free radical production [62].Increased glycolysis provides essential anabolic substrates, such as ribose for nucleic acid synthesis [63]. Glucose consumption through the pentose pathway may also provide essential reducing equivalents (NADPH) to reduce the toxicity of reactive oxygen species conferring resistance to senescence $[64,65]$. So cancer cells with a high glycolytic rate have an advantage in tumor growth [66].

This study necessitates repeat ion on larger animals and humans to be of value as a diagnostic tool.

In conclusion, our results implicated increased activities of the glycoregulatory enzymes, HK, GAPDH and G6PD of HMP shunt, alongside to alpha fetoprotein and liver premalignant changes in hepatocellular carcinoma bearing animals, compared to normal control. This indicated an elevated rate of glycolysis and HMP shunt during HCC. Therefore, we suggest that increased production of ribose through HMP and associated activities of the glycoregulatory enzymes (HK, GAPDH, and G6PD) may be used as new diagnostic tools for carcinogenesis in liver in combination with the ordinary candidates like AFP. The enzyme activities when elevated simultaneously in liver tissue and released to circulation may account further studies for legislation of glycoregulatory enzymes as new tumor markers for HCC or draw attention as additional biomarkers to elevate both sensitivity and specificity of the current tumor marker AFP.

\section{Financial disclosures}

This work was not supported by any grants.

\section{Conflict of Interest}

There are no conflicts of interest.

\section{Acknowledgement}

We appreciate the assistance and advice of Professor Manal Hashem, Department of Histopathology College of Medicine, Minia University, Egypt, for her kind cooperation in the interpretation of tissue microscopical investigations.

\section{References}

[1] Llovet JM (2005) Updated treatment approach to hepatocellular carcinoma. J Gastroenterol 40, 225-235. 
[2] El-Serag HB \& Rudolph KL (2007) Hepatocellular carcinoma: epidemiology and molecular carcinogenesis. Gastroenterology 132, 2557-2576.

[3] Llovet JM \& Bruix J. (2003) Systematic Review of Randomized Trials for Unresectable Hepatocellular Carcinoma: Chemoembolization Improves Survival. Hepatol 37, 429-442.

[4] Abdel-Hamid NM (2009) Recent insights on risk factors of hepatocellular carcinoma. World J Hepatol 1, 3-7.

[5] Bosch FX, Ribes J \& Diaz M CR (2004) Primary liver cancer: worldwide incidence and trends. . Gastroenterology 127, 5-16.

[6] Lai EC \& WY. L (2005) The continuing challenge of hepatic cance rin Asia. Surgeon 3, 210-215.

[7] Lau W \& EC L (2008) Hepatocellular carcinoma: current management and recent advances. Hepatobiliary Pancreat Dis Int 7, 237-257.

[8] Brown RS \& Wahl RL (1993) Overexpression of Glut-1 glucose transporter in human breast cancer. Cancer 72 2979-2985.

[9] Guillemin K \& Krasnow MA (1997) The hypoxic response: huffing and HIFing. Cell 89, 9-12.

[10] Wang GL, Jiang BH, EA R \& and Semenza GL (1995) Hypoxiainducible factor 1 is a basic-helix-loop-helix-PAS heterodimer regulated by cellular O2 tension. Proc Natl Acad Sci USA 92, 5510-5514.

[11] Beckner ME, Stracke ML, LA L \& and Schiffmann E (1990) Glycolysis as primary energy source in tumor cell chemotaxis. $J$ Natl Cancer Inst 82, 1836-1840.

[12] Greiner EF, M G \& Brand K (1994) Glucose is essential for proliferation and the glycolytic enzyme induction that provokes a transition to glycolytic energy production. J Biol Chem 269, 31484-31490.

[13] IARC. (2000) N-nitrosodiethanolamine. IARC Monogr Eval Carcinog Risks Hum. 77, 403-438.

[14] Loeppky RN (1999) The mechanism of bioactivation of Nnitrosodiethanolamine. Drug Metab Rev 31, 175-193.

[15] Abdel-Hamid NM, Nazmy MH \& Abdel-Bakey AI (2011) Polyol profile as an early diagnostic and prognostic marker in natural product chemoprevention of hepatocellular carcinoma in diabetic rats. Diabetes Res Clin Pract.

[16] Parimala R \& Sachdanandam P (1993) Effect of Plumbagin on some glucose matabolising enzymes studied in rats in experimental hepatoma. Mol Cell Biochem 125, 59-63.

[17] Harris RA (2004) Glycolysis, Overview. Encyclopedia of Biological Chemistry 2, 266-271.

[18] Shaw RJ (2006) Glucose metabolism and cancer. Current Opinion in Cell Biology 18, 598-608.

[19] Zhivotovsky B \& Orrenius S (2009) TheWarburg Effect returns to the cancer stage. Seminars in Cancer Biology 19, 1-3.

[20] Permalatha B, V S \& Sachdanandam (1997) Modulating effect of Semecarpus Anacardium L. nut extract on glucose metabolizing enzymes in aflatoxin B1-induced experimental Hepatocellular carcinoma. Pharmacological Research 36, 187-192.

[21] Sivanesan D \& Begum VH (2007) Modulating effect of Gynandropsis gynandra L on glucose metabolizing enzymes in aflatoxin B1-induced experimental Hepatocellular carcinoma in rats. Indian Journal of Biochemistry \& Biophysics 44, 477-480.

[22] Yuen M \& C L (2005) Serological markers of liver cancer. Best Practice \& Research Clinical Gastroenterology 19, 91-99.

[23] Dakshayani KB, Subramanian P, Manivasagam T \& Essa MM MS (2005) Melatonin modulates the oxidant-antioxidant imbalance during $\mathrm{N}$-nitrosodiethylamine induced hepatocarcinogenesis in rats. J Pharm Sci 8, 316-321.

[24] Singha BN, Braj R. Singhb, B.K. Sarmaa \& H.B. Singha (2009) Potential chemoprevention of N-nitrosodiethylamine-induced hepatocarcinogenesis by polyphenolics from Acacia nilotica bark. Chemico-Biological Interactions 181, 20-28.

[25] Subramanian P, 1 SM, Kadiyala Babu Dakshayani1 \& Seithikurippu R. Pandi-Perumal2 ITaDPC (2007) Prevention by melatonin of hepatocarcinogenesis in rats injected with $\mathrm{N}$ nitrosodiethylamine. J Pineal Res 43, 305-312.

[26] Bergmeyer HU, Grassl M \& HE W (1983) in Methods of Enzymatic Analysis (Bergmeyer, H.U. ed) 3rd ed., Verlag Chemie, Deerfield. In, pp. 222-223.

[27] Velick SF (1955) Methods Enzymol. In, pp. 401-406.

[28] kornberg A (1955) Methods in Enzymology. Acedemic Press, New york, 232.
[29] Gornall AG, Bardawill CJ \& MM D (1949) Determination of serum proteins by means of the biuret reaction. J Biol Chem 177, 751-766.

[30] Bergmeyer HU, Grassl, M., and Walter, H.E. (1983) Methods of Enzymatic Analysis Vol. Volume II, Verlag Chemie,, Deerfield Beach, FL.

[31] Llovet JM (2005) Updated treatment approach to hepatocellular carcinoma. J Gastroenterol 40, 225-235.

[32] Davis GL, Dempster J, Meler JD, Orr DW, Walberg MW, Brown B, Berger BD, O'Connor JK \& Goldstein RM (2008) Hepatocellular carcinoma: management of an increasingly common problem. Proc (Bayl Univ Med Cent) 21, 266-280.

[33] Abdel-Hamid M, El-Daly M, Molnegren V, El-Kafrawy S, AbdelLatif S, Esmat G, Strickland GT, Loffredo C, Albert J \& Widell A (2007) Genetic diversity in hepatitis C virus in Egypt and possible association with hepatocellular carcinoma. J Gen Virol 88, 15261531.

[34] Anwar WA, Khaled HM, Amra HA, H E-N \& CA L (2008) Changing pattern of hepatocellular carcinoma (HCC) and its risk factors in Egypt: Possibilities for prevention. Mutation Research 659, 176-184.

[35] Al-Rejaie SS, Aleisa AM, Al-Yahya AA, Bakheet SA, Alsheikh A, Fatani AG, Al-Shabanah OA \& MM A (2009) Progression of diethylnitrosamine-induced hepatic carcinogenesis in carnitinedepleted rats. World J Gastroenterol 15, 1373-1380.

[36] Sundaresan S \& P S (2003) S- allycysteine inhibits circulatory lipid peroxidation and promotes antioxidants in Nnitrosodiethylamine-induced carcinogenesis. polJ Pharmacol 55 , 37-42.

[37] Theise ND (1995) macroregenerative (dysplastic) nodules and hepatocarcinogenesis; theoretical and clinical consideration. Semin liver Dis 15, 360-371.

[38] Kondo Y (1997) pathology of early hepatocellular carcinoma and preneoplastic lesion in the liver. In: Okudak, Tabor E (eds.); liver cancer. New York, churchill Livingstone. 135-153.

[39] Lopez J (2005) Recent Developments in the first detection of Hepatocellular carcinoma Clin Biochem 26, 65-75.

[40] Sivaramakrishnan V, Shilpa PN, Praveen Kumar VR \& Niranjali Devaraj S (2008) Attenuation of N-nitrosodiethylamine-induced hepatocellular carcinogenesis by a novel favonol Morin. Chem Biol Interact 171, 79-88.

[41] Xu R, Pelicano H Z, hou Y CJ \& S FL, Bhalla KN, Keating MJ and Huang P, (): "I". ;: (2005) Inhibition of Glycolysis in Cancer Cells: A Novel Strategy to Overcome Drug Resistance Associated with Mitochondrial Respiratory Defect and Hypoxia. Cancer Res 65, 613-621.

[42] Schafer D, B H-K \& Brand K (1997) Glucose regulates the promoter activity of aldolase A and pyruvate kinase M2 via dephosphorylation of Sp1. FEBS Lett 417, 325-328.

[43] Izuishi K, Kato K, Ogura T \& Kinoshita T and Esumi H (2000) Remarkable tolerance of tumor cells to nutrient deprivation: possible new biochemical target for cancer therapy. Cancer Res $\mathbf{6 0}$, 6201-6207.

[44] Kato K, Ogura T, Kishimoto A \& Minegishi Y NN, Miyazaki M and Esumi H, (): "'.;(2000) Critical roles of AMP-activated protein kinase in constitutive tolerance of cancer cells to nutrient deprivation and tumor formation. Oncogene 21, 6082-6090.

[45] King CP (2004) Molecular imaging. Hepatocellular carcinoma screening, diagnosis, and management. National Institutes of Health, Bethesda, Maryland, 109-112.

[46] Dang CV \& Semenza GL (1999) Oncogenic alterations of metabolism. Trends Biochem Sci 24, 68-72.

[47] Selak MA, Armour SM, MacKenzie ED \& . ea (2005) Succinate links TCA cycle dysfunction to oncogenesis by inhibiting HIFalpha prolyl hydroxylase. Cancer Cell 7, 77-85.

[48] Katzen HM \& Schimke RT (1965) Multiple forms of hexokinase in the rat: Tissue distribution, age dependency, and properties. Proc NatlAcad Sci USA 54, 1218-1225.

[49] Kuang Y, Schomisch SJ, V C \& and Lee Z, (2006) Hexokinase and glucose-6-phosphatase activity in woodchuck model of hepatitis virus-induced hepatocellular carcinoma. Comparative Biochemistry and Physiology, Part C 143, 225-231.

[50] Mathupala SP, Rempel A \& Pedersen PL (1997) Aberrant glycolytic metabolism of cancer cells: a remarkable coordination of genetic, transcriptional, post-translational, and mutational events that lead to a critical role for type II hexokinase. $J$ Bioenerg Biomembr 29, 339-343. 
[51] Torizuka T, Tamaki N, Inokuma T \& Magata Y SS, Yonekura Y, Tanaka A, Yamaoka Y, Yamamoto K and Konishi J, (): ".18111817 (1995) In vivo assessment of glucose metabolism in hepatocellular carcinoma with FDG-PET. J Nucl Med 36, 18111817.

[52] Mazurek S, Eigenbrodt E, K F \& and Steinberg P (1999) Alterations in the glycolytic and glutaminolytic pathways after malignant transformation of rat liver oval cells. J Cell Physiol 181, 136-146.

[53] Nagashima RA, Paggi MG, LJ S \& and Pedersen PL (1988) Purification characterization of a bindable form of mitochondrial bound hexokinase from the highly glycolytic AS-30D rat hepatoma cell line. Cancer Res 48, 913-919.

[54] Katabi MM, Chan HL, SE K \& and Batist G (1999) Hexokinase type II: a novel tumor-specific promoter for gene-targeted therapy differentially expressed and regulated in human cancer cells. Hum Gene Ther 10, 155-164.

[55] Kuzminskaya EV, Asryants RA \& Nagradova NK (1993) SH containing compounds as allosteric effectors of glyceraldehyde-3phosphate dehydrogenase. FEBS Lett 336, 208-210.

[56] Shalova IN, Cechalova K, and RZ \& Dimitrova P (2007) Decrease of dehydrogenase activity of cerebral glyceraldehyde-3-phosphate dehydrogenase in different animal models of Alzheimer's disease. Biochimica et Biophysica Acta 1770, 826-832.

[57] Sirover MA (1997) Role of the Glycolytic Protein, Glyceraldehyde-3-Phosphate Dehydrogenase, in Normal Cell Function and in Cell Pathology. Journal of Cellular Biochemistry 66, $133-140$.

[58] Sirover MA (1999) New insights into an old protein: the functional diversity of mammalian glyceraldehyde-3-phosphate dehydrogenase. Biochim Biophys Acta 1432, 159-184.
[59] Shibuya A \& Ikewaki N (2002) High serum glyceraldehyde-3phosphate dehydrogenase levels in patients with liver cirrhosis. Hepatology Research 22, 174-179.

[60] Gordon GB, MC M \& Levy HR (1995) On the mechanism of interaction of steroids with human glucose-6-phosphate dehydrogenase. Arch Biochem Biophys 318, 25-29.

[61] Tian W, Braustein LD, Apse K PJ \& RM, Tian X and Staton RC, (1999) Importance of glucose-6-phosphate dehydrogenase activity in cell death. Am J Physiol Cell Physiol 276, 1121-1131.

[62] Coussens LM \& Werb Z (2002) Inflammation and cancer. Nature 420, 860-867.

[63] Homem de Bittencourt PI, Peres CM, Yano MM, Hiratea MH \& and Curi R (1993) Pyruvate is a lipid precursor for rat lymphocytes in culture: Evidence for a lipid exporting capacity. Biochem Mol Biol Int 30, 631-641.

[64] Kondoh H, Lieonart ME, Bernard D \& and Gil J (2007) Protection from oxidative stress by enhanced glycolysis; a possible mechanism of cellular immortalization. Histol Histopathol 22, 8590.

[65] Kondoh H, Lieonart ME, Gil J BD \& and Peters G (2005) Glycolysis and cellular immortalization. Drug Discov Today 2, 263-267.

[66] Peng S, Lai P, Pan H \& Hsiao L and Hsu H (2008) Aberrant expression of the glycolytic enzymes aldolase B and type II hexokinase in hepatocellular carcinoma are predictive markers for advanced stage, early recurrence and poor prognosis. ONCOLOGY REPORTS 19, 1045-1053. 